\title{
Estudo qualitativo da integração ensino-serviço em um curso de graduação em Odontologia *
}

Ana Luiza de Souza ${ }^{1}$

Daniela Lemos Carcereri²

SOUZA, A.L.; CARCERERI, D.L. Qualitative study of the teaching-service integration in an undergraduate Dentistry course. Interface - Comunic., Saude, Educ., v.15, n.39, p.1071-84, out./dez. 2011.

This qualitative study aimed to investigate, through individual and group interviews, the teaching-service integration between a public university in southern Brazil and the public health services. The data were analyzed following the Thematic Content Analysis. Two thematic axes and four categories emerged. The thematic axis called Activator grouped aspects developed in the program, and the axis under Construction revealed the difficulties that were observed. The identified categories were: Teaching-Service Partnership; Curricular Structure; Paradigm Change; and Teaching Practices. It was concluded that the participants understand the teaching-service integration as a potential strategy that can contribute to the process of change of practices in health education, although there are resistant groups. The curricular restructuring collaborated to develop new actions in education, as well as to improve the teaching and service integration.

Keywords: Teaching-care integration services. Dental education. Dental staff.
Este estudo, de abordagem qualitativa, investigou, por meio de entrevistas individuais e em grupo, a integração ensino-serviço entre uma universidade pública do sul do Brasil e os serviços públicos de saúde. Os dados foram analisados sob a Análise Temática de Conteúdo, e, na análise, emergiram dois eixos temáticos e quatro categorias. $\mathrm{O}$ eixo temático Ativador agrupou aspectos desenvolvidos no programa e o eixo em Construção revelou as dificuldades observadas. As categorias identificadas foram: Parceria Ensino-Serviço; Estrutura Curricular; Mudança de Paradigma e Práticas Pedagógicas. Conclui-se que os participantes compreendem a integração ensino-serviço como potencial estratégia colaboradora do processo de mudança de práticas na formação em saúde, apesar de haver grupos resistentes. $O$ processo de mudança de práticas se desenvolveu ativamente a partir da reestruturação curricular. A integração ensino-serviço é um dos eixos que busca solidificar a proposta curricular, por meio de ações diversas na interface do ensino com o serviço.

Palavras-chave: Serviços de Integração docente-assistencial. Ensino de Odontologia. Recursos humanos em Odontologia.

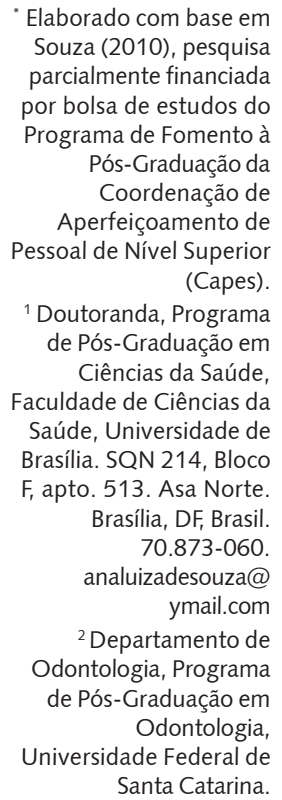




\section{Introdução}

A inadequação da formação em saúde ao longo do tempo tem gerado consequências prejudiciais ao sistema de saúde e à saúde da população, como: o desequilíbrio entre oferta e demanda de profissionais, a má-distribuição, as dificuldades de fixação, as competências e o conhecimento limitado, o desenvolvimento de estratégias equivocadas de gestão frente à realidade do serviço e à demanda populacional (Brasil, 2009). É no descompasso que existe entre a formação dos profissionais e as necessidades da população que está a grande barreira da relação Serviços de Saúde/Ensino em Saúde (González, Almeida, 2010).

Dentre as características que contribuíram para a inadequação da formação dos profissionais de saúde está a fragmentação de conteúdos e a centralização do professor especialista no processo ensinoaprendizagem. Essa configuração do ensino privilegia a excessiva especialização e o distanciamento do profissional de saúde da preparação para o cuidado resolutivo e contínuo à população (Albuquerque et al., 2009). Campos et al. (2009) consideram a aprendizagem centrada no professor socialmente irresponsável, devido à postura passiva dos participantes (estudantes, docentes e gestores) neste processo.

Desde o Movimento de Reforma Sanitária Brasileira, diversas iniciativas têm sido propostas para enfrentar este descompasso entre as necessidades da população e o caráter formativo em saúde, dentre elas a reestruturação do processo de formação dos recursos humanos. Um marco histórico para a reorientação da formação em saúde foi a promulgação da Constituição Brasileira, em 1988, que, no Artigo 200, dispõe que o Ministério da Saúde é responsável pela ordenação da formação de recursos humanos na área da saúde (Brasil, 2007). O Quadro 1 sumariza eventos importantes da última década no Ensino em Odontologia.

Desde então, o governo tem se comprometido a cumprir a legislação, porém, isto tem sido feito com emprego variável de recursos e em diferentes intensidades. Uma das vertentes importantes da reestruturação é a integração ensino-serviço, que envolve: o quadro docente das universidades, os trabalhadores da saúde, a reorganização curricular dos cursos de graduação e pós-graduação, e o estabelecimento de vínculos com os serviços públicos de saúde.

A integração ensino-serviço é compreendida como eixo do processo pedagógico, integra a universidade aos serviços de saúde, privilegia o estudante, seus conhecimentos, expectativas e experiências no processo de ensino-aprendizagem. O conteúdo programático do curso é elaborado de acordo com a prática em situação real de ensino e com o ambiente de trabalho. Portanto, o estudante tem a oportunidade de unir seus conhecimentos à prática do serviço e refletir sobre seu papel e atitudes junto à comunidade (Morita, Haddad, 2008; Pereira, Ramos, 2006; Yoder, 2006).

Os currículos precisam ser construídos e reconstruídos cotidianamente com o intuito de promover efetivas mudanças no Ensino Superior, priorizando o pensamento, a crítica e a criatividade (Lemos,

Quadro 1. Eventos históricos que marcaram o ensino da Odontologia na última década

\begin{tabular}{|l|l|}
\hline 1988 & $\begin{array}{l}\text { Constituição Federal - Saúde na Constituição } \\
\text { Regulamentação do Sistema Único de Saúde }\end{array}$ \\
\hline 1990 & Sancionada Lei Orgânica da Saúde \\
\hline 1993 & Il Conferência Nacional de Saúde Bucal \\
\hline 2002 & Aprovação das Diretrizes Curriculares Nacionais para o Curso de Odontologia \\
\hline 2003 & Criação da Secretaria de Gestão do Trabalho e da Educação na Saúde \\
\hline 2004 & $\begin{array}{l}\text { III Conferência Nacional de Saúde Bucal } \\
\text { Criação do Fórum Nacional de Educação das Profissões na Área da Saúde (FNEPAS) }\end{array}$ \\
\hline 2005 & Criação do Pró-Saúde (SGTES) \\
\hline 2008 & Criação do PET-Saúde e UNA-SUS (SGTES) \\
\hline
\end{tabular}


Fonseca, 2009). O foco deve ser na aprendizagem, oportunizando, ao estudante, a possibilidade de transformar, elaborar, integrar o novo conhecimento ativamente, rompendo com esquema de aulas e avaliação fechada (Campos et al., 2009).

As novas DCN são o eixo orientador do atual projeto político-pedagógico de um curso de graduação em Odontologia, em uma universidade pública situada no sul do Brasil. Os incentivos do Pró-Saúde e do PET-Saúde ampliaram o espaço de discussão entre a universidade e os serviços públicos de saúde e a representatividade da integração ensino-serviço no cotidiano de ambas as instituições.

O início das atividades junto aos serviços de saúde nesta universidade aconteceu na década de 1970, no contexto do movimento nacional na época denominado integração docente-assistencial. Atualmente, a universidade conta com a chamada Rede Docente Assistencial, responsável pelo processo de articulação ensino-serviço, da qual participam profissionais da Secretaria Municipal de Saúde, docentes, estudantes e representantes dos Conselhos de Saúde (SMS, 2008).

A última reestruturação curricular do curso de graduação em Odontologia foi oficializada em 2006, com a aprovação de um projeto político-pedagógico que reúne dois eixos principais: o eixo interdisciplinar, ou da interação comunitária, e o eixo multidisciplinar. No eixo da interação comunitária, as atividades de integração ensino-serviço se iniciam no segundo semestre e se desenvolvem até o oitavo semestre, no âmbito da atenção básica. Posteriormente, a atuação dos estudantes contempla serviços de média e alta complexidade até o final do curso, no décimo semestre. As atividades desenvolvidas no serviço são orientadas por docentes e preceptores que acompanham os estudantes nos cenários de prática (Coordenadoria do Curso de Graduação em Odontologia, 2006).

O currículo propõe aprendizagem construtivista, onde o estudante é responsável por seu aprendizado e o docente é o orientador do processo. As disciplinas são organizadas em eixos integrados e a formação ocorre em clínicas integradas de complexidade crescente, nos serviços e na comunidade. Há combinação de estratégias de ensino-aprendizagem de acordo com as características socioculturais da instituição, da sociedade e das necessidades dos estudantes (Alonso, Antoniazzi, 2010). O professor não é mais o centro do processo pedagógico e a doença é substituída pela saúde como estrutura fundamental do processo de aprendizagem (Campos et al., 2009).

Este importante desafio a ser vencido pela universidade na ressignificação dos processos de ensinar aprender - atuar deve ser acompanhado por meio de estratégias que possibilitem o direcionamento adequado das ações. Frente a esse contexto, justifica-se compreender a integração ensino-serviço a partir da percepção de seus participantes, procurando identificar os fatores que direcionam e/ou distanciam o referido Curso de Graduação em Odontologia da operacionalização de seu atual projeto político pedagógico.

\section{Percurso metodológico}

Utilizou-se a metodologia qualitativa, e os dados foram coletados através da realização de entrevistas individuais e em grupo. Os métodos qualitativos têm sido aplicados de forma adequada para responder temas complexos, com os quais pesquisadores em saúde se confrontam, como a avaliação de reformas e mudanças organizacionais para oferta dos serviços de saúde, sob o ponto de vista de pacientes, profissionais de saúde e administradores (Pope, Mays, 2005). Segundo Flick (2004, p.28), "A pesquisa qualitativa é orientada para a análise de casos concretos em sua particularidade temporal e local, partindo das expressões e atividades das pessoas em seus contextos locais".

A seleção dos participantes para as entrevistas foi intencional, seguiu a lógica dos objetivos do estudo e o envolvimento dos participantes com o objeto de investigação. No âmbito dos serviços de saúde, envolveu gestores e cirurgiões-dentistas preceptores dos estudantes, nos cenários de prática dos serviços públicos de saúde. No âmbito da instituição de ensino, envolveu gestores, docentes e estudantes. Os estudantes participantes do estudo foram aqueles que se encontravam inseridos no novo currículo e que, no momento da coleta de dados, realizavam atividades nos serviços públicos de saúde. Portanto, participaram estudantes do primeiro ao quinto semestre do curso de graduação em Odontologia. 
A pesquisa totalizou 14 participantes — número determinado pelo procedimento de saturação teórica dos dados, baseado nos critérios de resposta aos objetivos do estudo, recorte do objeto do estudo e referencial teórico (Yin, 2005). As entrevistas tiveram uma duração média de quarenta minutos, foram registradas com o auxílio de um gravador de voz digital, e estruturadas a partir de um roteiro de questões norteadoras, cujo foco foi o programa de integração ensino-serviço.

Esse estudo foi realizado em observância à norma 196/96 do Conselho Nacional de Saúde e suas complementares, com aprovação junto ao Comitê de Ética e Pesquisa em Seres Humanos.

Após a coleta dos dados e transcrição das entrevistas, as informações foram analisadas seguindo os pressupostos da Análise Temática de Conteúdo. A análise perpassou por três etapas principais: préanálise, exploração do material, tratamento dos resultados obtidos e interpretação junto ao referencial teórico. Durante a pré-análise foi realizada leitura flutuante do material, e estabelecimento das unidades de registro (categorização inicial). A fase de exploração do material procurou atingir o núcleo de compreensão do texto, através da classificação das informações em categorias e especificação dos eixos temáticos (Minayo, 2006; Bardín, 1979).

\section{Resultados e discussão}

A análise das informações possibilitou a identificação de dois eixos temáticos: um eixo ativador e um eixo em construção. O eixo temático ativador é aquele onde se encontram os aspectos desenvolvidos, em direção à reflexão e mudança de práticas. Por outro lado, o eixo em construção representa a face em desenvolvimento, onde se encontram as dificuldades e entraves observados em diferentes dimensões do processo.

Os eixos temáticos orientaram a identificação de quatro categorias: parceria ensino-serviço; estrutura curricular; mudança de paradigma; e práticas pedagógicas. Aliados ao referencial teórico, os dados geraram o seguinte esquema (Figura 1).

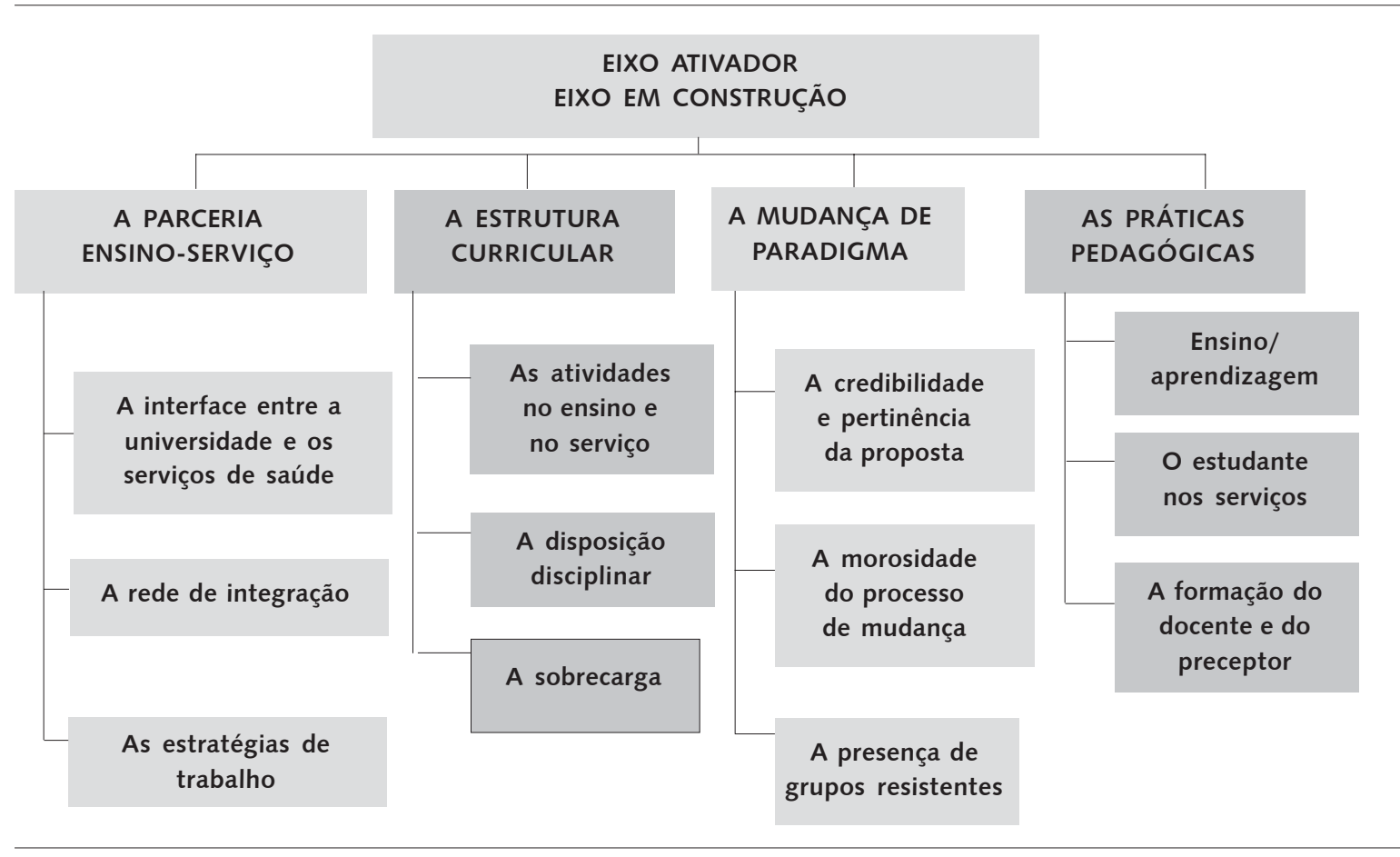

Figura 1. Esquema ilustrativo dos eixos temáticos e categorias 
Os resultados são descritos a seguir, acompanhados da discussão, divididos entre as categorias analisadas. Fragmentos de entrevistas acompanham a discussão e estão em destaque.

\section{Parceria ensino-serviço}

A integração ensino-serviço faz parte de um processo de reflexão de práticas curriculares, planos e conteúdos de ensino, que têm sido consolidados à medida que o curso de graduação em Odontologia avança em semestres.

O estabelecimento da parceria entre a Universidade e os serviços públicos de saúde obteve maior representatividade à medida que as questões curriculares foram motivadas pelas Diretrizes Curriculares Nacionais e por programas colaboradores, como o Pró-Saúde e o PET-Saúde (Brasil, 2009, 2005, 2002; Silva, 2008). Surgiu, então, a Rede de Integração, dotada de regimento próprio e membros diretores de ambas as instituições, o que possibilitou o estabelecimento de relações de trabalho diferenciadas e a possibilidade de tomada de decisões pactuadas. São exemplos de tais decisões: a escolha dos locais de atuação dos estudantes nos cenários de prática e a aplicação de recursos do Pró-Saúde e do PET-Saúde. A decisão sobre as unidades de saúde que recebem os estudantes considera: a garantia de estabilidade das atividades do serviço com a presença do ensino, a disponibilidade dos cirurgiões-dentistas da unidade em atuar na preceptoria, a estrutura física e pessoal da unidade, a necessidade social e o interesse à formação.

Para modificar o contexto da parceria entre universidade e serviço, as instituições pesquisadas têm investido na ampliação e aprimoramento da estrutura física do serviço, na formação dos preceptores, na realização de pesquisas no nível da atenção básica e na atuação dos estudantes em diferentes ocasiões, potencializando atividades de prevenção, educação e recuperação da saúde. As experiências de integração vivenciadas até o momento foram agradáveis aos participantes, e os gestores se destacam como principais articuladores do processo.

Feuerwerker e Sena (2002) ponderam as características essenciais de uma proposta de inovação curricular: a organização curricular em módulos integrados, baseados em problemas extraídos da realidade; metodologias ativas de ensino-aprendizagem; prática nos serviços, interação com a comunidade desde o início do curso e avaliação permanente do processo. Estas características se fazem presentes no Curso analisado por este estudo e de maneira crescente têm sido consolidadas.

A universidade participa do Programa PET-Saúde. O programa PET foi idealizado como uma das ações intersetoriais potencializadoras do Pró-Saúde, pois favorece a atuação pedagógica na atenção básica, com o envolvimento de preceptores, docentes e estudantes. Visa o desenvolvimento de pesquisas, práticas de atenção e formação dos estudantes e preceptores. Reforça a importância da desconcentração de papéis e responsabilidades, e da formação pedagógica para atuação dos preceptores como educadores e participantes ativos do desenvolvimento curricular (Brasil, 2009, 2008; Silva, 2008; Schmidt, 2008). Tais iniciativas fortalecem a corresponsabilização das instituições: a universidade na prestação do cuidado e os serviços na atuação junto à formação (Albuquerque et al., 2008).

De acordo com Araújo e Zilbovicius (2008); Morita e Haddad (2008) e Silva (2008), as atividades que intencionam a integração teórico-prática, o trabalho em equipe e a prestação de cuidado integral à saúde têm a possibilidade de potencializar a formação, a reorganização do modelo de atenção e o enfrentamento das necessidades em saúde da população. A integralidade do ensino em saúde afirma a formação pautada no cuidado humanizado e na promoção da saúde (González, Almeida, 2010).

A combinação de critérios utilizada na parceria universidade/serviço é julgada adequada frente ao proposto pelo Ministério da Saúde e da Educação, e às diretrizes do Pró-Saúde (Brasil, 2008, 2005). A integração, através da Rede de Integração, é um pilar importante das atividades entre ensino e serviço, pois se trata de uma proposta formalizada. Segue os desígnios da Lei 8.080/1990 (Artigo 14), que diz que deverão ser criadas comissões permanentes de integração entre os serviços de saúde e as instituições de ensino profissional e superior, com o intuito de cooperar técnica e cientificamente e para proposição de prioridades na formação e na educação permanente (Brasil, 1990). Tais direcionamentos vão ao encontro da Lei de Diretrizes e Bases para a Educação Superior e das Diretrizes Curriculares Nacionais (Brasil, 1990, 2002). 


\section{Estrutura curricular}

As incursões dos estudantes nos cenários de prática ocorrem desde o segundo semestre do curso de graduação em Odontologia, onde são desenvolvidas atividades na atenção básica. Entretanto, os níveis secundário e terciário de atenção (média e alta complexidade) são contemplados somente após o sexto semestre do curso.

Previamente às atividades de campo, existe uma fase de planejamento e orientação teórica, onde docentes, preceptores e estudantes contribuem na definição das atividades a serem executadas e têm a oportunidade de manifestar sua opinião.

“E aí a gente está participando nesse processo junto, em alguns momentos nós até comentamos que agora estamos tendo que ajudá-los [os estudantes] a decidir o que eles vão pesquisar. Claro que sempre tentamos pensar o que será útil para eles e que também possa dar um retorno para nós no Centro de Saúde, como muitos aqui tiveram, nos trabalhos, nas pesquisas. Isso foi algo bastante enriquecedor". (preceptor B)

Por outro lado, existem algumas atividades sem planejamento, que fazem com que o encaminhamento dos estudantes seja diretamente aos cenários de prática, sem que haja um diálogo prévio com o serviço, o que prejudica a dinâmica das atividades.

"Eu vejo que às vezes existe algum conflito, porque a Universidade quer que eles [referindo-se aos estudantes] façam determinada coisa, mas que na prática não condiz com a nossa realidade. Então acaba criando um certo conflito ou um desconforto entre o serviço e a Universidade". (preceptor $\mathrm{C}$ )

As atividades no início do curso ficam centradas na atenção básica, um espaço privilegiado para a exploração do ambiente, da unidade de saúde, dos recursos e da dinâmica da comunidade. Os exercícios focam, sobretudo, o diagnóstico da situação de saúde da população, e não o enfrentamento de problemas pelos estudantes. Nos semestres mais avançados, o programa prevê que os estudantes executem atividades variadas em todos os níveis de atenção, direcionadas à Odontologia e à saúde geral, com participação em grupos de promoção e educação em saúde. Tal planejamento está em concordância com os direcionamentos relatados por Morita e Haddad (2008).

Entre as atividades já realizadas pelos estudantes, destacam-se aquelas fundamentadas na epidemiologia geral e bucal, bioestatística, planejamento, programação e avaliação em saúde bucal, aplicadas à comunidade. O reconhecimento da estrutura do serviço e a coleta de dados epidemiológicos são atividades relevantes na formação direcionada aos serviços públicos de saúde. Os estudantes anseiam pela possibilidade de ampliarem sua atuação na comunidade:

“Então eu acho que o trabalho é importante, não tem que parar, mas pode se tornar bem melhor, pode ampliar. E não só no sentido que eu estou fazendo agora de ajudar os outros, não. Quando eu estiver na sexta fase quero fazer uma coisa maior ainda, tentar resolver os problemas". (estudante D)

As atividades das disciplinas da Saúde Pública/Coletiva têm recebido atenção diferenciada pelos estudantes, que têm as enfrentado com mais seriedade, apresentando-se mais participativos e ativos.

"Ali eu sinto que há uma diferença de interesse pela disciplina, os alunos comparecem a aula, a participação deles na aula, comentários e tudo mais. O que para mim é diferente, é novo, e eu estou atribuindo a esta mudança toda que já começou no currículo deles". (docente B)

A atribuição de valores às disciplinas precisa ser conduzida de maneira equilibrada. Historicamente, as disciplinas que envolvem aspectos biológicos e intervenções clínicas recebem maior investimento e 
ganham destaque no currículo. Já as disciplinas que propõem reflexões e ações no campo da ética e das ciências humanas recebem pouca atenção (Albuquerque et al., 2009). Este é um dos paradigmas que a nova estrutura curricular pretende modificar, trazendo, aos estudantes, tais disciplinas equilibradamente na formação contextualizada.

Os estudantes reconhecem que as disciplinas encontram-se articuladas e percebem a relação existente entre a formação social e técnica, posicionando o conhecimento sobre o SUS como parte global da formação (Araújo, Zilbovicius, 2008). Tais achados estão consoantes com os relatos de Matos e Tomita (2004), que realizaram entrevistas com estudantes e concluíram que, apesar da permanência da visão mercadológica, há concepção ampliada da Saúde Coletiva.

As atividades de planejamento criam espaços coletivos de discussão, onde as propostas podem ser acompanhadas, avaliadas e tornam-se motivadoras para o comprometimento dos participantes (Schmidt, 2008). A formação pautada na integralidade deve associar estágios na atenção básica a outros campos de produção da saúde, durante todo o curso. Diversas escolas têm direcionado as atividades da mesma maneira que o curso observado neste estudo, o que se percebeu como uma atitude relevante, porém não eficaz na integração dos campos de conhecimento da profissão e multiprofissionais (Brasil, 2008).

A avaliação do Ministério da Saúde prevê que, mesmo em fases iniciais do curso, é importante que os estudantes percebam a integração entre os níveis de assistência, para que sejam capazes de desenvolver habilidades que possibilitem a produção de níveis crescentes de saúde na população, equilibrando ações sociais e formação técnica. Dessa maneira, cria-se oportunidade para o enfrentamento de diferentes problemas, em todos os cenários onde ocorre a prática profissional (Araújo, Zilbovicius, 2008; Brasil, 2008; Morita, Haddad, 2008).

As atividades em cenários de prática, aliadas ao conteúdo teórico do Curso, geram alta carga horária semanal, diminuindo a flexibilidade curricular, limitando a participação dos estudantes em projetos de extensão e pesquisa, que poderiam contribuir com a sustentabilidade das mudanças (Brasil, 2008). A alta carga de atividades também traz sobrecarga ao trabalho dos gestores, docentes e preceptores. Esta dificuldade foi relatada por Lemos e Fonseca (2009), que realizaram entrevistas - e, unanimemente, os entrevistados criticaram a elevada carga horária semanal, que limita o tempo de dedicação ao estudo e a atividades extras. Um dos entrevistados considerou a carga horária um verdadeiro "massacre pedagógico".

Neste estudo, os preceptores relataram que a formação profissional até então não fazia parte da agenda de trabalho, e que o acréscimo de mais uma função sobrecarrega a estrutura do serviço. Tais considerações também são relatadas por González e Almeida (2010).

\section{Mudança de paradigma}

Há certeza de objetivos pelos participantes.

“Não dá para nós querermos que hoje esteja desse jeito e amanhã de outro. O currículo mudou então amanhã já vai ser diferente. Não! A coisa é gradativa. Temos que nos fortalecer com as pequenas mudanças que acontecem, que daí tu tá vendo que antes não era assim e agora já é. Então já melhorou. Então não está sendo em vão". (gestor B)

A credibilidade e a pertinência das ações são percebidas pelos participantes do programa de integração ensino-serviço, que sentiam necessidade da mudança de práticas:

"Mas por muito tempo eu sonhei em ter estudantes que vissem o que acontece na realidade [...]. Normalmente ele não imagina aquilo ali, ele não sabe como se articula um serviço de saúde, como se trabalha em equipe, como se conhece a população, como se consegue fazer atenção básica para uma determinada região, ele não tem essa noção. Por mais que ele aprenda na Universidade o que é o SUS, ele vai ver a realidade lá no serviço". (preceptor A) 
Uma das características desejáveis na formação é o desenvolvimento de capacidades para o trabalho multiprofissional e interdisciplinar. Ferreira et al. (2006) destacam que a solidariedade deve estar presente entre os atuantes na equipe, para que compartilhem saberes e práticas. No curso de graduação em Odontologia analisado por este estudo, até o momento não foi possível organizar atividades intercursos que estimulariam o trabalho interdisciplinar, devido à dificuldade em conciliar o horário das disciplinas e dos docentes e à capacidade física limitada de algumas unidades de saúde. Para reverter esse quadro, está sendo realizado um movimento através da Rede de Integração, onde os coordenadores dos cursos de Enfermagem, Medicina, Odontologia e outros cinco cursos da área da saúde discutem a possibilidade de se articularem momentos comuns de aprendizagem.

"Se tiver dentro duma Unidade só estudantes da Odontologia, é uma realidade, se você tiver uma equipe de saúde que envolve a Odonto, Medicina e quem sabe, futuramente, Fisioterapia, Nutrição, etc.; você possa fazer um trabalho conjunto das várias especialidades em prol de um objetivo comum, em benefício da instituição, do aluno e da comunidade". (preceptor A)

Segundo o Relatório do II Seminário Nacional do Pró-Saúde, o arranjo para o direcionamento de atividades multiprofissionais pode ser feito através de: alocação dos estudantes nos mesmos campos de estágio; desenvolvimento conjunto de atividades entre diferentes cursos da área da saúde; atividades de extensão e pesquisa; e interação em ambientes onde há Residência Multiprofissional em Saúde da Família. Outro dispositivo é a criação de disciplinas ou módulos integradores como promotores de atuação coletiva.

A qualificação dos profissionais de saúde para o trabalho multiprofissional é um objetivo a ser alcançado. As atividades práticas nas comunidades devem ser priorizadas entre os profissionais, para que a organização do trabalho em equipe reconheça a limitação de um único profissional para atender as necessidades de saúde do indivíduo e da comunidade, em todos os níveis de atenção à saúde (LochNeckel et al., 2009).

Percebe-se o conflito entre o novo e o velho, a busca por novas maneiras de praticar, formar e produzir conhecimento em saúde. A reforma traz questões que direcionam a construção de sujeitos coletivos e ao êxito das ações em saúde (Feuerwerker, Sena, 2002). Compreende-se que o processo de reflexão de práticas é gradativo e moroso, visto o enraizamento das práticas vigentes. A morosidade das mudanças acompanha o processo de reforma do setor saúde, induzidas pelo SUS e suportadas por movimentos sociais e recursos financeiros (Araújo, Zilbovicius, 2008).

\section{Práticas pedagógicas}

Percebe-se a concordância dos participantes com a reflexão sobre as atividades, entretanto essa anuência não é unânime. Os interesses mercadológicos prevalecem nas falas de alguns estudantes. Esta mesma conduta foi observada por Lemos e Fonseca (2009).

\footnotetext{
“Vai influenciar para pessoas que não conhecem a profissão. Meu pai é dentista também, entende? Eu acho que ele já tem uma carreira, já tem a clínica e eu vou usufruir disso. Mas uma pessoa que não tem essa base vai... Hoje em dia o mercado está acirrado, muitos dentistas. Eu acredito que essas pessoas, por exemplo, muita gente da nossa sala, vai para o postinho, vão fazer PSF, essas coisas... Porque o mercado está difícil, tem que ser muito bom para ganhar clientela, essas coisas. Eu acho que a tendência é essa, o pessoal tentar procurar emprego no PSF, se encaixar no SUS". (estudante C)
}

Existe a divisão de opiniões dos estudantes entre favoráveis e desfavoráveis à mudança. Aqueles que acreditam na mudança consideram a formação atual um diferencial de empregabilidade no futuro, e os demais não consideram que a reestruturação curricular pode contribuir de alguma maneira na sua formação. 
“Eu sempre achei esse currículo novo a melhor opção. E se eu tivesse entrado no currículo antigo e tivesse vendo o currículo novo acontecer, eu iria voltar, assim como um monte de gente já voltou, eu iria voltar, a despeito de me formar antes, entrar no mercado de trabalho. Eu tenho noção de que o meu currículo é muito melhor para o meu futuro". (estudante D)

O grupo de docentes também se apresenta heterogêneo quanto à concordância com as mudanças curriculares.

“É porque são pessoas que se formaram há muito tempo, que sempre atuaram em clínica privada, que a perspectiva deles é o consultório privado. [...] Alguns desqualificam todo o esforço tanto da coordenação quanto dos outros profissionais que estão, mas eu acho que é isso, a gente precisa estar tensionando". (docente A)

Alguns estudantes consideram as atividades nos cenários de prática a parte mais importante do curso, que aliadas à orientação teórica, oportunizam um olhar crítico ao Sistema, fundamentado na aprendizagem contextualizada.

"Então eu acho que com essas atividades a pessoa vê um outro jeito do SUS. Então ela tem uma experiência ótima. Porque aí a gente saiu ótimo, vendo o SUS perfeito para trabalhar. Nós achávamos que o SUS era tudo largado... O que a gente viu foi uma coisa bem organizada e isso vai nos ajudar bastante, não só pensando em atender no particular, como nos Postos de Saúde". (estudante A)

O depoimento acima representa a visão dos estudantes sobre os serviços públicos, considerando-os de baixa qualidade e insuficientes. Tal percepção é relatada por Santa-Rosa et al. (2007), que realizaram grupos focais e observaram a modificação dessa visão após as atividades de campo, assim como observado entre alguns estudantes envolvidos neste estudo. Os gestores e os trabalhadores dos serviços públicos percebem tal impressão no grupo de estudantes e docentes, gerando desconforto na relação ensino/serviço (preceptor/estudante/docente).

“E acho que ainda existe o problema do preconceito, esse é muito forte. De que existe uma Odontologia de consultório e uma Odontologia de serviço público. [...] Ele pode não ser claro, mas tu percebes que existe essa visão de que no serviço público é algo, vamos dizer assim, de menor qualidade. Então que se nós trabalharmos com nossos alunos para eles irem para as Unidades, que eles vão sair profissionais com menos qualidade, menos formados. É triste". (gestor A)

No presente estudo, tanto os preceptores quanto os docentes encontram-se fragilizados e necessitam de formação para atuar de maneira mais resolutiva na nova lógica curricular. A relação entre preceptores e docentes é percebida como a mais delicada entre os participantes do programa, e pode ser fortalecida por meio de atividades conjuntas que estimulem o conhecimento um do outro, a troca de saberes e o compartilhamento de responsabilidades.

As dificuldades no processo fazem com que os preceptores sintam-se desestimulados com as atividades no ensino, e isso reflete no seu aproveitamento e participação. O grupo de docentes também vivencia dificuldades em relação às atividades de campo, demonstrando resistência em acompanhar os estudantes nos cenários de prática e no aceite da proposta de mudança.

Na comunidade, os estudantes realizam atividades que dinamizam o trabalho da equipe de saúde, instigando atitudes crítico-reflexivas dos profissionais.

"Então existe uma riqueza bastante grande dessa presença dos alunos ali dentro da Unidade de Saúde e não só pela pesquisa, mas também as intercorrências trazem muitos benefícios para eles, e para a gente. Querendo ou não, dá uma reflexão tanto do profissional que está ali dentro tanto dos alunos, porque entra em choque de informações e de realidade". (preceptor C) 
Toassi (2008) observou que a resistência frente à implantação de um currículo modular foi manifestada principalmente por docentes, enquanto os estudantes se mostraram receptivos e avaliaram positivamente a mudança. No presente estudo foi observado que os docentes apresentam resistência em relação à modificação de suas práticas de ensino, e alguns estudantes não se sentem sensibilizados e inseridos na proposta, concordando com os achados de Schmidt (2008).

Historicamente, o professor de Odontologia é o profissional bem-sucedido, com disponibilidade para o ensino. As necessidades provenientes da atividade docente no contexto educacional atual demandam, além da formação técnica, a didático-pedagógica (González, Almeida, 2010). A formação do professor é um desafio para as instituições de Ensino Superior e depende da motivação pessoal e, sobretudo, institucional. Com a falta de motivação, os professores desenvolvem sua profissionalidade docente de forma empírica e intuitiva, baseados, especialmente, em experiências pessoais (Bazzo, 2007). Percebese a necessidade de formação dos docentes na dimensão didático-pedagógica. Sobretudo, os docentes devem se dispor a atuar de forma diferente, ensinar e aprender de modo diferente, pois a conduta inovadora no processo de ensino-aprendizagem requer a utilização de metodologias de ensino que estimulem a participação dos estudantes, como protagonistas do aprendizado, e posicionem os docentes e preceptores como orientadores (Schmidt, 2008; Toassi, 2008; Moysés, 2004).

Um dos grandes acréscimos trazidos com a formação aliada ao serviço é o conhecimento dos serviços públicos de saúde como realmente estão estruturados (Moysés, 2004). Outro benefício importante proveniente das atividades de campo é o contato com a comunidade, que proporciona a oportunidade de percepção do indivíduo, inserido no meio social, possibilitando a formação humanizada em saúde (Araújo, Zilbovicius, 2008).

O processo de corresponsabilização deve ser fortalecido. No serviço, facilitaria o envolvimento dos preceptores e buscaria o envolvimento dos gestores das unidades de saúde. No ensino, a corresponsabilização pelo serviço traz a possibilidade de potencializá-lo (Araújo, Zilbovicius, 2008; Morita, Haddad, 2008). Tais dificuldades também se encontram presentes no relatório do seminário nacional do Pró-Saúde, que sugere a formação técnica e pedagógica dos docentes (Brasil, 2008).

De acordo com González e Almeida (2010, p.760), "identificar a necessidade de mudança, buscar novos conceituais e explorar práticas inovadoras" são elementos indispensáveis, mas não suficientes para superar o paradigma hegemônico instalado nas instituições de ensino. É preciso aproximação e comprometimento de todos os participantes, fazendo com que as mudanças cheguem às salas de aula.

Observa-se que todas as categorias sinalizam aspectos ativadores e em construção do programa de integração ensino-serviço. Para sintetizar e tornar mais clara a visualização dos resultados, foi elaborado um esquema posicionando os dados em relação aos eixos temáticos (Quadro 2).

Quadro 2. Quadro-síntese dos resultados aliados aos eixos temáticos

\begin{tabular}{|l|l|}
\hline \multicolumn{1}{|c|}{ EIXO ATIVADOR } & \multicolumn{1}{c|}{ EIXO EM CONSTRUÇÃO } \\
\hline Rede de integração universidade/serviço: trabalho intersetorial & Institucionalização da proposta \\
\hline Bom relacionamento entre gestores: articulação do processo & Definição de papéis dos participantes \\
\hline Novas práticas na dinâmica ensino/serviço & Sobrecarga de atividades \\
\hline Formação dos estudantes & Alta carga horária curricular \\
\hline $\begin{array}{l}\text { Inserção nos cenários de prática: aliam necessidades do ensino e } \\
\text { do serviço }\end{array}$ & Deficiência na variabilidade dos cenários de prática \\
\hline Planejamento conjunto das atividades & Heterogeneidade da relação docente/preceptor \\
\hline Receptividade dos participantes & Presença de grupos resistentes \\
\hline Busca por equacionar falhas e dificuldades & Corresponsabilização do ensino e do serviço \\
\hline Há certeza de objetivos: credibilidade e pertinência das açães & Formação de docentes e preceptores \\
\hline Metodologias de ensino-aprendizagem & Atividades multiprofissionais intercursos \\
\hline
\end{tabular}




\section{Considerações finais}

Com este estudo, foi possível compreender, a partir da percepção dos participantes, a integração ensino-serviço entre os serviços públicos de saúde e o curso de graduação em Odontologia, de uma universidade localizada no sul do Brasil. A categoria parceria ensino-serviço destaca-se como eixo ativador, enquanto os demais aspectos observados dividem-se entre o eixo ativador e em construção. A integração ensino-serviço é percebida como potencial estratégia colaboradora do processo de mudança de práticas na formação em saúde, apesar de haver grupos resistentes.

O processo de mudança de práticas se desenvolveu ativamente a partir da reestruturação curricular e da reforma do projeto político-pedagógico do curso. A integração ensino-serviço é um dos eixos que buscam solidificar a proposta curricular, através de ações diversas na interface do ensino com o serviço.

A formalização da integração ensino-serviço, através da rede de integração, é uma potencialidade que colabora com o diálogo entre as instituições, os gestores e os demais participantes do processo pedagógico, fortalecendo a relação interinstitucional. As atividades de integração têm tido uma articulação adequada entre as instituições, e as dificuldades fazem parte do processo de mudança e têm sido corrigidas conforme o progresso do curso, em diferentes momentos, após exaustivas avaliações e discussões.

As atividades previstas dentro da nova dinâmica curricular demandam mais tempo e dedicação dos participantes. Os estudantes sentem-se limitados pela alta carga horária do curso para dedicarem-se a atividades extras, como projetos de extensão, pesquisa e estágios. Os preceptores sentem dificuldade em aliar suas atividades regulares ao ensino, o que pode ser amenizado com a adesão de mais profissionais. Já no caso dos docentes, para distribuição das atividades, está sendo realizada a ampliação do quadro docente, por meio da contratação de professores efetivos e substitutos.

A sobrecarga dos espaços físicos do ensino e, sobretudo, do serviço tem sido amenizada com o investimento de recursos, advindos sobretudo do Pró-Saúde, na ampliação, equipamento e melhoria dos ambientes utilizados pelos estudantes.

Os cenários de prática estão concentrados na atenção básica e inserem os estudantes nas unidades de saúde. Observou-se a necessidade de inclusão de maior variedade de cenários de prática nos períodos iniciais do curso, pois é importante que os estudantes percebam, desde o início, a aplicabilidade dos princípios da integralidade.

Também são necessárias atividades motivadoras de enfrentamento de problemas em saúde pelos estudantes. Atualmente, as atividades nos cenários de prática focam o diagnóstico, o reconhecimento da comunidade e suas características. Espera-se, com o decorrer do curso, desenvolver atividades que motivem os estudantes ao enfrentamento de problemas e situações adversas em saúde, para o desenvolvimento de características de autonomia profissional.

A formação dos estudantes se percebe diferenciada em relação às disciplinas de caráter social, ao contato com a comunidade e ao conhecimento do Sistema Único de Saúde. Tais direcionamentos são adequados frente ao previsto pelo Ministério da Saúde e da Educação (Brasil, 2009).

Evidenciam-se as novas abordagens de ensino-aprendizagem, como a utilização de metodologias que estimulam a participação ativa dos estudantes e propõem uma avaliação processual frente à proposta de ensino.

A receptividade dos participantes frente à proposta se mostrou heterogênea; alguns são muito favoráveis, no entanto, existe a presença de grupos resistentes, especialmente entre os docentes. A dissolução desses posicionamentos poderia ser realizada através da divulgação do projeto e do contexto em que está envolvido (parte de um movimento nacional e mundial) para todos os participantes. Dessa maneira facilitaria a conscientização da dimensão dos acontecimentos e da necessidade iminente da participação.

Os docentes precisam ser capacitados para atuação fora da universidade, para o acompanhamento das atividades dos estudantes nos cenários de prática. Os preceptores precisam de formação didáticopedagógica para interação adequada com os estudantes nos serviços públicos de saúde.

De modo geral, observou-se que todas as dificuldades identificadas pelo estudo têm sido enfrentadas. Apesar das resistências e fragilidades, a perspectiva futura é positiva. Como caminhos a 
seguir, visualizam-se: a necessidade de capilarizar o projeto através da divulgação, desenvolver ambientes de diálogo entre os participantes, para que compartilhem conquistas e dificuldades; e oferecer atividades de formação.

Para acompanhamento e avaliação totalizadora do curso, recomenda-se a realização de estudo semelhante quando as atividades curriculares inovadoras contemplarem todos os semestres. Os novos estudos podem incluir os gestores das unidades de saúde e a comunidade nas entrevistas, visto que esta foi uma limitação do presente estudo.

A integração ensino-serviço mostra-se fundamental para a operacionalização do atual projeto político pedagógico do curso de Odontologia envolvido neste estudo.

Dentre as soluções para os problemas encontrados na relação entre as instituições estudadas, destaca-se a longitudinalidade das ações. A continuidade e conclusão do projeto de reforma curricular em curso contribuirão para a consolidação dos espaços de diálogo construídos e para uma maior integração entre os envolvidos durante o planejamento, realização e avaliação das atividades pedagógico-assistenciais.

\section{Colaboradores}

Ana Luiza de Souza realizou a pesquisa do referencial teórico, a coleta e análise dos dados; elaborou o relatório da pesquisa e o artigo. Daniela Lemos Carcereri participou como orientadora durante todas as fases da pesquisa e da elaboração do manuscrito.

\section{Referências}

ALBUQUERQUE, V.S. et al. Currículos disciplinares da área da saúde: ensaio sobre saber e poder. Interface - Comunic., Saude, Educ., v.13, n.31, p.261-72, 2009.

A integração ensino-serviço no contexto dos processos de mudança na formação superior dos profissionais de saúde. Rev. Bras. Educ. Med., v.32, n.3, p.35662, 2008.

ALONSO, M.S.; ANTONIAZZI, J.H. (Coord.) Livro do Projeto Latino-Americano de Convergência em Educação Odontológica (PLACEO). São Paulo: Artes Médicas, 2010.

ARAUJO, M.E.; ZILBOVICIUS, C. A formação acadêmica para o trabalho no Sistema Único de Saúde (SUS). In: MOYSÉS, S.T.; KRIGER, L.; MOYSÉS, S.J. (Orgs.). Saúde bucal das famílias: trabalhando com evidências. São Paulo: Artes Médicas, 2008. p.277-90.

BARDIN, L. Análise de conteúdo. Lisboa: Edições 70, 1979.

BAZZO, V.L. Constituição da profissionalidade docente: desafios e possibilidades. 2007. Tese (Doutorado) - Programa de Pós-Graduação em Educação, Universidade Federal do Rio Grande do Sul, Porto Alegre. 2007.

BRASIL. Ministério da Saúde. Secretaria de Gestão do Trabalho e da Educação na Saúde. A Educação e o Trabalho na Saúde: A Política e suas Ações. Brasília: Ministério da Saúde, 2009.

Ministério da Saúde. Ministério da Educação. Secretaria de Gestão do Trabalho e da Educação na Saúde. Relatório do II Seminário Nacional do Programa de Reorientação da Formação Profissional em Saúde - Pró-Saúde. Brasília: Ministério da Saúde, 2008. 
BRASIL. Constituição da República Federativa do Brasil: texto constitucional promulgado em 05 de outubro de 1988, com as alterações adotadas pelas Emendas Constitucionais $n^{\text {os }} 1 / 92$ a 53/06 e pelas Emendas Constitucionais de Revisão nos 1 a 6/ 94. Brasília: Senado Federal, Subsecretaria de Edições Técnicas, 2007.

Ministério da Saúde. Ministério da Educação. Portaria Interministerial MS/MEC 2.101, de 03 de novembro de 2005. Institui o Programa Nacional de Reorientação da Formação Profissional em Saúde (Pró-Saúde) para os cursos de graduação em Medicina, Enfermagem e Odontologia. Diário Oficial da União, Brasília, DF, 2005. Seção 1, p. 111.

Ministério da Educação. CNE Conselho Nacional de Educação. Câmara de Educação Superior. Resolução CNE-CES 3, de 19/02/2002. Institui as Diretrizes Curriculares Nacionais do Cursos de Graduação em Farmácia e Odontologia. Diário Oficial da União, Brasília, DF, 4 de março de 2002. Seção 1, p.10.

Lei $n^{\circ} 8.080$, de 20 de setembro de 1990. Dispõe sobre as condições para a promoção, proteção e recuperação da saúde, a organização e o funcionamento dos serviços correspondentes e dá outras providências. Diário Oficial da União, Brasília, DF 20 set. 1990. Seção 1, p.18.055.

CAMPOS, F.E. et al. O SUS como escola: a responsabilidade social com a atenção à saúde da população e com a aprendizagem dos futuros profissionais de saúde. Rev. Bras. Educ. Med., v.33, n.4, p.513-4, 2009.

COORDENADORIA DO CURSO DE GRADUAÇÃO EM ODONTOLOGIA. Projeto político-pedagógico do curso de graduação em Odontologia. Florianópolis: CCO, 2006.

FERREIRA, E.F. et al. Travessia a caminho da integralidade: uma experiência do curso de odontologia da UFMG. In: PINHEIRO, R.; CECCIM, R.B.; MATTOS, R.A. (Orgs.). Ensino-trabalho-cidadania: novas marcas ao ensinar integralidade no SUS. Rio de Janeiro: UERJ, IMS/Abrasco, 2006. p.85-91.

FEUERWERKER, L.; SENA, R. Contribuição ao movimento de mudança na formação profissional em saúde: uma avaliação das experiências UNI. Interface - Comunic., Saude, Educ., v.6, n.10, p.37-50, 2002.

FLICK, U. Uma introdução à pesquisa qualitativa. 2.ed. Porto Alegre: Bookman, 2004.

GONZÁLEZ, R.D.; ALMEIDA, M.J. Integralidade da saúde: norteando mudanças na graduação dos novos profissionais. Cienc. Saude Colet., v.15, n.3, p.757-62, 2010.

LEMOS, C.L.S.; FONSECA, S.G. Saberes e práticas curriculares: um estudo de um curso superior na área da saúde. Interface - Comunic., Saude, Educ., v.13, n.28, p.57-69, 2009.

LOCH-NECKEL, G. et al. Desafios para a ação interdisciplinar na atenção básica: implicações relativas à composição das equipes de saúde da família. Cienc. Saude Colet., v.14, n.1, p.1463-72, 2009.

MATOS, P.E.S.; TOMITA, N.E. A inserção da Saúde Bucal no Programa de Saúde da Família: da universidade aos pólos de capacitação. Cad. Saude Publica, v.20, n.6, p.1538-44, 2004.

MINAYO, M.C.S. O desafio do conhecimento: pesquisa qualitativa em saúde. 9.ed. São Paulo: Hucitec, 2006.

MORITA, M.C.; HADDAD, A.E. A concepção pedagógica e as Diretrizes Curriculares Nacionais: interface da área da Educação e da Saúde na perspectiva da formação e do trabalho das equipes da Saúde da Família. In: MOYSÉS, S.T.; KRIGER, L.; MOYSÉS, S.J. (Orgs.). Saúde Bucal das Famílias: trabalhando com evidências. São Paulo: Artes Médicas, 2008. p.268-76. 
MOYSÉS, S.J. Políticas de saúde e formação de recursos humanos em Odontologia. Abeno, v.4, n.1, p.30-7, 2004.

PEREIRA, I.B.; RAMOS, M.N. Educação profissional em saúde. Rio de Janeiro: Fiocruz, 2006.

POPE, C.; MAYS, N. Pesquisa qualitativa na atenção à saúde. 2.ed. Porto Alegre: Artmed, 2005.

SANTA-ROSA, T.T.A.; VARGAS, A.M.D.; FERREIRA, E.F. O internato rural e a formação de estudantes do curso de Odontologia da UFMG. Interface - Comunic., Saude, Educ., v.11, n.23, p.451-66, 2007.

SCHMIDT, S.M.S. O processo de formação dos cursos de graduação em enfermagem, medicina e odontologia, nos serviços de atenção básica 2008. Tese (Doutorado) Universidade Federal de Santa Catarina, Florianópolis. 2008.

SILVA, E.V.M. A formação de profissionais da saúde em sintonia com o SUS: currículo integrado e interdisciplinar. Núcleo de Gestão do Trabalho e Educação na Saúde do CONASEMS. Brasília: Ministério da Saúde, 2008.

SMS. Secretaria Municipal de Saúde. Histórico da Rede Docente-Assistencial. Disponível em: <http://www.pmf.sc.gov.br/saude/>. Acesso em: 18 maio 2008.

SOUZA, A.L. Integração ensino-serviço no curso de graduação em Odontologia da Universidade Federal de Santa Catarina. 2010. Dissertação (Mestrado) - Centro de Ciências da Saúde, Programa de Pós-Graduação em Odontologia, Universidade Federal de Santa Catarina, Florianópolis. 2010.

TOASSI, R.F.C. O embate do processo de implantação de um currículo modular na educação superior: o curso de Odontologia da UNIPLAC, Lages-SC. 2008. Tese (Doutorado) - Pontifícia Universidade Católica do Rio Grande do Sul, Porto Alegre. 2008.

YIN, R.K. Estudo de caso: planejamento e métodos. 3.ed. Porto Alegre: Artmed, 2005.

YODER, K.M. A framework for service-learning in dental education. J. Dental Education, v.70, n.2, p.115-23, 2006.

SOUZA, A.L.; CARCERERI, D.L. Estudio cualitativo de la integración docencia-servicio en un curso de graduación de Odontología. Interface - Comunic., Saude, Educ., v.15, n.39, p.1071-84, out./dez. 2011.

Este estudio cualitativo ha investigado, mediante entrevistas individuales y grupales, la integración docencia-servicio entre una universidad pública en el sur de Brasil y los servicios públicos de salud. Los datos fueron analizados mediante el análisis de contenido, y los resultados mostraron dos ejes temáticos principales y cuatro categorías: el eje temático activador agrupa aspectos desarrollados en el programa y el eje en construcción revela las dificultades observadas. Las categorías identificadas han sido: asociación docencia-servicio: estructura curricular; cambio de paradigma y prácticas pedagógicas. Se concluyó que los participantes entienden la integración docenciaservicio como potencial estrategia colaboradora para el cambio de prácticas en educación en salud, aunque hay grupos resistentes. El proceso de cambio de prácticas se ha desarrollado activamente después de la reestructuración curricular. La integración docencia-servicio es uno de los ejes que tiene por objeto consolidar el plan de estudios a través de diversas acciones en la articulación de la enseñanza con el servicio.

Palabras clave: Servicios de integración docente-asistencial. Enseñanza de Odontología. Recursos humanos en Odontología. 